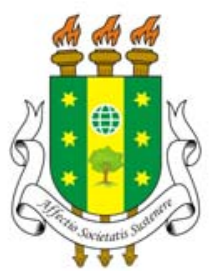

educationis

Journal homepage:

www.arvore.org.br/seer

\section{DESCOBRINDO AS PARASITOSES: JOGO EDUCATIVO PARA O ENSINO DE CIÊNCIAS}

\section{RESUMO}

No município de Boquim, Sergipe, há presença de casos de doença de chagas, leishmaniose e esquistossomose. Diante das restrições ocorridas nos livros didáticos, das formas tradicionais com que são lecionados os assuntos pertinentes à parasitologia, foi elaborado um jogo educativo baseado nas dificuldades identificadas no conhecimento do aluno, da didática do professor e da apresentação do livro adotado pelo Colégio Cleonice Soares Fonseca, situado no município citado. Para a construção desse recurso foi aplicado um questionário ao professor na tentativa de descobrir suas dificuldades para lecionar as parasitoses. Outro questionário foi aplicado aos alunos com perguntas referentes ao assunto em estudo para verificar o nível de informações pré-existentes sobre os mesmo e análise do livro. $O$ jogo dispõe de cartelas com dicas relacionadas às doenças, estimula a capacidade de dedução e curiosidade investigativa dos participantes, podendo ser adotado em sala de aula ou até mesmo pelos alunos sozinhos. Assim, podemos considerá-lo com um recurso de auxílio no ensino-aprendizagem dos estudantes sobre doenças parasitológicas.

PALAVRAS-CHAVE: Parasitologia; Ensino-Aprendizagem; Jogo Educativo.

\section{DISCOVERING THE PARASITOSIS: EDUCATIONAL GAME FOR SCIENCE EDUCATION.}

\section{ABSTRACT}

In the Boquim municipality, Sergipe, there are cases of Chagas disease, leishmaniasis and schistosomiasis. Given the constraints that occur in textbooks, and based on the traditional forms that are taught subjects relevant to parasitology was produced an educational game based on problems identified in the student's knowledge of the didactics of the teacher and the book presentation adopted by the College Cleonice Soares Fonseca located in the city said. To build this application was applied a questionnaire to the teacher in an attempt to discover their difficulties to teach parasites. Another questionnaire to students with questions pertaining to the subject being studied to determine the level of pre-existing information on and analysis of the same book. The game features cards with tips related to diseases, stimulates the ability of deduction and investigative curiosity of the participants and may be adopted in the classroom or even the students themselves. So we can consider it with an appeal for aid in the teaching-learning students on parasitological diseases.

KEYWORDS: Parasitology; Teach of sciences; Educative games.
Educationis, Aquidabã, v.2, n.1, Ago, Set, Out, Nov, Dez 2013, Jan 2014.

\section{ISSN 2318-3047}

\section{SECTION: Articles}

TOPIC: Práticas, Didática e

Metodologias do Ensino

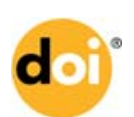

DOI: 10.6008/ESS2318-3047.2014.001.0003

Fabrícia Fraga Trindade Universidade Federal de Sergipe, Brasil fa.trindade@hotmail.com

Mario André Trindade Dantas Universidade Federal de Minas Gerais, Brasil http://lattes.cnpq.br/2337213908856661 matdantas@yahoo.com.br

\section{Christiane Ramos Donato}

Universidade Federal de Sergipe, Brasil http://lattes.cnpq.br/1035573410272594 christianecrd@yahoo.com.br

\section{Fabiana Silva Vieira}

Universidade Federal da Bahia, Brasil http://lattes.cnpq.br/7924741218127218 fabiannavieira@yahoo.com.br

Received: 17/12/2013

Approved: 15/01/2014

Reviewed anonymously in the process of blind peer.

\section{Referencing this:}

TRINDADE, F. F.; DANTAS, M. A. T.; DONATO, C. R.; VIEIRA, F. S.. Descobrindo as parasitoses: jogo educativo para o ensino de ciências. Educationis, Aquidabã, v.2 n.1, p.26-34, 2014. DOI: http://dx.doi.org/10.6008/ESS23183047.2014.001.0003 


\section{INTRODUÇÃO}

As doenças infecciosas e parasitárias ainda são causa de morte nos países da América Latina e na África. Essas doenças encontram-se, portanto, entre os grandes problemas médicossanitários dos países em desenvolvimento, a exigir consideráveis recursos financeiros, organização, e pessoal habilitado para combatê-las (REY, 2008).

Atingem mais gravemente as populações submetidas à falta de infraestrutura adequada, com deficiência na higiene pessoal, falta de informação específica para prevenção e baixa renda. A habitação dessas pessoas, assim como praças, escolas e residências sem saneamento básico são os locais que oferecem mais risco de contaminação (TOSCANI et al., 2007).

A Organização Mundial de Saúde (OMS) estabelece políticas públicas, propondo e apoiando campanhas, elaborando planos nacionais de emergência e de investimentos, promovendo debates de princípios, estratégias e compromissos que favorecem o desenvolvimento de habilidades pessoais e coletivas visando à melhoria de vida e saúde da população (TOSCANI et al., 2007). Percebe-se, portanto, a importância de criar atividades de Educação em Saúde. A sensibilização e prevenção, aliados à ampliação da infraestrutura, devem estar diretamente ligadas a esses domicílios, permitindo melhores condições de saúde e de vida.

Uma alternativa de sensibilização dos alunos seria a utilização de atividades lúdicas, através de: teatros, jornais informativos, histórias em quadrinhos e jogos (ALMEIDA, 2007; MORAN, 2008) que podem promover uma absorção de conteúdos mais prazerosa. Essas intervenções educativas podem estimular ações que contribuam para uma melhor forma de ensino sobre doenças parasitárias, com consequentes resultados positivos na aprendizagem do aluno, o que contribuirá também para a prevenção desse tipo de infecções (TOSCANI et al., 2007). Tendo em vista este quadro, o presente trabalho propõe o uso de uma metodologia que busca passar o conteúdo programático apresentado no sétimo ano sobre parasitologia através da utilização de um jogo lúdico.

\section{REVISÃO TEÓRICA}

\section{Jogo Educativo}

Os educadores se ocuparam por muitos anos com os métodos de ensino, procurando quais seriam os meios adequados, os procedimentos necessários para atingir a reflexão e a compreensão da realidade, alcançando assim o objetivo do processo de ensino-aprendizagem. Somente hoje a preocupação está sendo descobrir como a criança aprende. As mais variadas metodologias podem ser ineficazes se não forem adequadas ao modo de aprender da criança (LOPES, 2005). 
Jogos educativos são aqueles que "promovem situações de ensino-aprendizagem e aumentam a construção do conhecimento, introduzindo atividades lúdicas e prazerosas, desenvolvendo a capacidade de iniciação e ação ativa e motivadora" (FIALHO, 2008). De uma forma geral, os jogos fazem parte de nossa vida desde os tempos mais remotos, estando presentes não só na infância, mas em outros momentos (TAROUCO et al., 2004). E é a partir de estudos da psicologia de cada fase de desenvolvimento do ser humano, que se percebe a importância do jogo em relação a manifestações motoras, instintivas e mentais da criança (ALMEIDA, 2007).

O jogo em si possui componentes do cotidiano e o envolvimento desperta o interesse do aprendiz, que se torna sujeito ativo do processo (LOPES, 2005). Jogar é participar do mundo de faz de conta, dispor-se às incertezas e enfrentar desafios em busca de entretenimento (TAROUCO et al., 2004). O jogo permite troca de informações, troca de ideias para que assim possam adquirir novas experiências e construir novos conceitos.

Através da aplicação dos jogos pode ser trabalhada a ansiedade do aluno, pois é um fator que pode atrapalhar: a concentração destes nas aulas; o relacionamento com os colegas, pois este influencia a autoestima, podendo assim prejudicar o aprendizado; os limites que muitas vezes não são bem administrados pelos pais, pois o jogo desenvolve noções de obediência às regras (LOPES, 2005).

Análises da postura de alunos que utilizaram jogos educativos nos mostram que a proposta do jogo é efetivamente mobilizadora, pois eles se empenharam na tentativa de descobrir as respostas e tornando-se cada vez mais familiarizados com os termos do tema educativo, citando como exemplo o trabalho de Lima (2002). O jogo desenvolve a capacidade criativa, a autonomia, coordenação motora, organização, o raciocínio lógico (LOPES, 2005). Piaget também faz sua defesa ao uso de jogos na educação, pois para ele é necessário suscitar indivíduos inventivos, críticos e criadores (ALVES, 2006).

O jogo para a criança é o exercício, é a apresentação para a vida adulta. A criança aprende brincando, é o exercício que a faz desenvolver suas potencialidades (LOPES, 2005). A criança que não sabe brincar será um adulto que não saberá pensar (CHATEAU, 1987 apud ALMEIDA, 2007).

\section{METODOLOGIA}

$\mathrm{Na}$ tentativa de auxiliar e facilitar o ensino/aprendizagem é proposta a criação de um jogo educativo que aborde, de forma mais dinâmica, as doenças parasitológicas de maior incidência no município de Boquim, Sergipe. Foi escolhido o Colégio Estadual Cleonice Soares Fonseca, localizada em Boquim, região centro-sul de Sergipe, pois nele são atendidos, na sua maioria, escolares residentes em zona rural, onde as condições de proliferação dessas parasitoses são maiores. O trabalho foi realizado com alunos do sétimo ano, em que o tema "seres vivos" é 
abordado, em especial protozoários e helmintos transmissores das principais doenças parasitológicas de maior incidência no município.

Para analisar as dificuldades encontradas pelos alunos, foi aplicado um questionário. Optou-se por dois tipos de questões: as abertas e as de múltipla escolha. As primeiras nos proporcionam comentários, explicações e esclarecimentos significativos para se interpretar e analisar, já as de múltipla escolha nos apresenta uma maior facilidade de aplicação e de análise. Foi através desse recurso que analisamos o nível dos alunos em relação ao tema de estudo, assim como também as dificuldades encontradas pelo professor para lecionar o assunto.

O livro didático da Série Link da Ciência adotado pelo colégio também foi analisado, por ser uma das fontes mais importantes de conhecimentos para os alunos. Buscou-se conhecer como o mesmo faz menção sobre o assunto e qual a importância dada pelo livro a essas doenças na tentativa de educar sobre a proliferação, profilaxia e tratamento. A partir das dificuldades encontradas foi elaborado um jogo educativo 'descobrindo as parasitoses' inspirado no jogo de perguntas e respostas perfil júnior 2 da GROW, em que através de dicas, o jogador tenta descobrir a resposta. Vence aquele que utilizarem menos dicas. Esse jogo estimula a capacidade de dedução e curiosidade investigativa dos participantes, podendo ser adotado em sala de aula ou até mesmo pelos alunos sozinhos.

A criação do jogo foi idealizada como forma de facilitar o aprendizado do aluno sobre o tema parasitoses como também uma forma de auxiliar ao professor na fixação do assunto explanado anteriormente. Após a aplicação dos questionários aos alunos, analisou-se a dificuldade em diferenciar conceitos de sintoma, contaminação, diagnósticos e imunização, a partir disso decidiu-se que estas seriam as categorias escolhidas acrescentando mais uma que falava sobre curiosidades completando cinco categorias para cada doença a ser trabalhada. Partindo desse princípio iniciamos o levantamento bibliográfico para a construção das dicas necessárias em cada cartela. Foram pesquisadas as três doenças e relacionamos suas características separando por cada categoria anteriormente definida.

Depois decidimos que seriam cinco dicas por cartela utilizando um critério numérico, ou seja, contabilizando quantas características cada doença dispunha. As cartelas foram confeccionadas no computador depois recortadas de igual tamanho. O tabuleiro e as fichas azuis e vermelhas foram confeccionados com EVA, cola e caneta e os peões e as regras foram utilizadas do jogo na versão original.

O jogo pode ter dois a seis participantes ou ainda pode ser jogado por duas até seis equipes. Contém 30 cartelas, um tabuleiro, seis peões, cinco fichas vermelhas e três fichas azuis. Cada cartela possui cinco dicas das categorias determinadas, curiosidades, contaminação, diagnóstico, sintomas e imunização. São duas cartelas de uma categoria para cada doença trabalhada.

Os jogadores devem reconhecer as doenças através de uma série de dicas reveladas uma a uma. O objetivo do jogo é ser o primeiro jogador ou a primeira equipe a levar o respectivo peão 
até o espaço marcado 'chegada'. As cartelas de dicas devem ser embaralhadas, as fichas azuis e vermelhas devem ficar ao lado do tabuleiro, cada jogador escolhe um peão e coloca-o no espaço do tabuleiro onde está marcada 'saída'.

Os jogadores decidem entre si quem começará a jogar. Esse jogador será o mediador, depois esse retira uma carta e diz aos outros qual a categoria. O jogador à esquerda do mediador escolhe um número de um a cinco e, coloca uma ficha vermelha sobre a casa no tabuleiro de mesmo número. O mediador lê em voz alta a dica de número escolhido pelo jogador.

Após a leitura da dica, o jogador que escolheu o número tem direito a dar um palpite sobre a identidade da cartela, dizendo em voz alta que doença ele pensa que é. Caso o jogador não queira dar o seu palpite, ele simplesmente passa a vez ao jogador à sua esquerda.

Se o jogador acertar o palpite, o mediador devolve a cartela ao final da pilha, avança os peões e retira as fichas vermelhas que estiverem sobre o tabuleiro. O jogador à esquerda, então, é quem passa a ser o mediador.

Se o jogador erra o palpite a vez de jogar passa para o próximo jogador à esquerda, que fará o mesmo que o anterior. Não há penalidade para o jogador que errar o palpite. Cada cartela vale 5 pontos divididos entre o jogador e o mediador. O mediador recebe um ponto por cada dica revelada e o jogador um ponto por cada dica não utilizada.

O jogador pode receber uma instrução ao invés de uma dica, como: perca a sua vez; avance ou volte ' $x$ ' casas; escolha um jogador para avançar ou voltar ' $x$ ' casas; e um palpite a qualquer hora, em que o jogador recebe uma ficha azul, que the permite dar um palpite imediatamente antes da jogada de outro participante ao longo de todo o jogo, isto é, antes que o adversário escolha uma nova dica. Isso não lhe tira o direito de dar um palpite na sua jogada, além do seu palpite normal. Depois de usada, a ficha é devolvida à mesa.

No tabuleiro terão fichas marcadas com '?' quem cair nelas terá direito a uma carta bônus, ou seja, o mediador escolhe uma nova cartela e o jogador poderá escolher as cinco dicas, uma por vez, porém se ele utilizar apenas uma dica ele recebe dez pontos, duas dicas oito pontos, três dicas seis pontos, quatro dicas quatro pontos e cinco dicas um ponto. Nesse caso, o mediador não ganha ponto. O primeiro jogador a chegar ao espaço marcado "chegada" será o vencedor. Não é preciso chegar lá com o número exato.

\section{RESULTADOS E DISCUSSÃO}

\section{Análise do Livro Didático}

A análise do livro didático, Série Link da Ciência adotado pela escola nos permitiu comprovar as opiniões dadas pelos professores que utilizam o mesmo. O livro é bastante resumido. No entanto, apesar de sucinto ele busca trazer de forma contextualizada seus conteúdos, sempre em formas de historinhas, apresentando muitas imagens, esquemas, textos 
complementares, no que aparenta ser uma tentativa de tornar o ensino de Ciências mais agradável.

Porém o livro falha pela falta de conceitos que muitas vezes se fazem necessários para melhor esclarecimento do assunto. Suas propostas de atividades propõem maior envolvimento do aluno como, por exemplo, sugerindo que elabore, pesquise ou entreviste. Assim retira o aluno do mundo de perguntas diretas e repostas prontas para assim instigar suas curiosidades, organizar suas ideias, raciocinar e construir conceitos, tornando-se um ser crítico.

\section{Análise dos Questionários}

A professora que leciona na turma do $7^{\circ}$ ano do Colégio Cleonice Soares Fonseca não é formada em Ciências Biológicas, portanto, não está habilitada a lecionar a disciplina. A análise da docente foi feita através de questionário em que se adotou parâmetros como formação acadêmica, habilidade em lecionar o tema, importância social do tema, contribuição da escola, utilização de recurso didático. Diante das respostas percebe-se que existe uma grande dificuldade em virtude da sua não formação acadêmica na área. A professora entende que o aluno é também um mediador entre a escola e a sociedade, refletindo assim a importância desses para com a cidadania. Aluno bem informado resulta em família bem informada. Concorda que o professor tem um papel importante e pode sim contribuir com a disseminação mais efetiva do assunto através de recursos alternativos, como os utilizados pelos próprios representantes da saúde. Acha muito relevante lecionar o assunto, visto que é um problema que se manifesta na cidade se tornando um problema público e a professora como cidadã pode contribuir para erradicar tais problemas.

Após autorização da direção e equipe pedagógica da escola, aplicaram-se os questionários individuais a 44 alunos do $7^{\circ}$ ano do Ensino Fundamental em horário de aula normal com o auxílio da professora de Ciências. Porém, é importante salientar que os mesmos ainda não tinham visto o assunto relacionado à parasitologia.

O questionário apresentava 5 questões objetivas e 5 subjetivas todas se referindo a doenças como esquistossomose, doença de chagas e leishmaniose. Usamos como parâmetros conceitos de sintomas, causas e prevenção, conhecimento popular e importância de saber identificar essas doenças. Percebemos a dificuldade de discernir ao certo o significado de sintomas, causas e prevenção, isso pode ser justificado, pois o assunto não havia sido explanado pelo professor. Na maioria, das perguntas subjetivas recebemos respostas como 'Nunca ouvi falar', 'Já ouvi falar', ou 'não lembro'. Mesmo não sabendo ou não lembrando todas as questões objetivas relacionadas às subjetivas tinham ao menos uma alternativa respondida.

Das cinco subjetivas, obtivemos $17 \%$ corretas, $42 \%$ erradas, $3 \%$ não responderam e $38 \%$ ouviram falar, mas não lembravam. O número significativo de alunos errou podendo assim ser justificado pela ausência do conteúdo. Os que não lembravam, porém já ouviram falar, pode ser referente ao conhecimento popular ou proveniente da aprendizagem temporária. Das cinco 
objetivas obtivemos $28,6 \%$ corretas, $56,3 \%$ erradas, $2 \%$ não responderam e $13,1 \%$ ouviram falar, mas não lembravam. A porcentagem de acertos aumentou em relação à subjetiva podendo ser justificada pela presença de opções para respostas. O percentual de erro continuou muito alto, provavelmente pela ausência da explanação de conteúdo referente ao assunto em estudo.

\section{Análise da Apresentação do Recurso}

Estando o jogo pronto fomos apresentar o recurso aos alunos do sétimo ano, turma ' $A$ ' do Colégio Cleonice Soares Fonseca. A turma estava agitada, com o auxílio da professora de Ciências todos foram acomodados e foi explicada a importância deles no trabalho, afinal foi através das respostas fornecidas por eles no questionário que foi possível a construção daquele recurso. Foi apresentado o recurso, as regras e notou-se que as expressões eram de ânimo e entusiasmo.

Assim que teve inicio a explicação das regras do jogo todos os olhares se tornaram atentos. Em se tratando de jogo, para os alunos é diversão, muitas vezes eles não conseguem perceber que estão aprendendo, raciocinando, articulando seu conhecimento.

Esclarecidas todas as regras foi sugerido que os alunos se dividissem em cinco equipes de nove pessoas, em que cada grupo teria um líder. Feita essa organização teve início o jogo. Na primeira jogada percebeu-se atenção e entusiasmo, assim continuou durante todo o momento da aula.

Para avaliar em que medida o jogo pode auxiliar na aprendizagem de doenças parasitológicas, observamos durante todo o jogo as expressões, o comportamento e os comentários dos alunos. Essa mesma análise foi feita por Lima (2002) quando observou a postura de seus alunos ao utilizarem jogos educativos, comprovando que a proposta do jogo de fato é mobilizadora.

A participação das equipes foi de grande importância, não havia dica sequer citada que eles não discutissem para, assim, darem seus palpites. Observou-se a cada jogada esse comportamento de interesse e empolgação, durante as conversas entre si.

Alguns alunos sentados mais distantes no início não se interessaram, porém, durante o percorrer do jogo e ao ver a empolgação dos seus colegas, ficaram curiosos e cada vez mais se aproximavam e começavam a discutir com suas equipes.

Quando os 50 minutos de aula se passaram eles estavam liberados para o recreio, mas resolveram continuar o jogo. Assim que passou o tempo do recreio finalizou-se o jogo e as expressões observadas foram de lamentação. Logo a coordenação já havia sido informada do sucesso do jogo pelos alunos e professores de outras disciplinas solicitaram a visualização do jogo, demonstrando interesse para aplicá-los em seus conteúdos. 
Durante a aplicação do recurso percebeu-se que mais interessante ficaria se houvesse um número maior de parasitoses trabalhadas no jogo ao invés de três, pois suas características são muito parecidas tornando as dicas mais difíceis, o que dificulta a resposta do aluno.

\section{CONCLUSÕES}

Pode-se concluir que houve aceitação do recurso por parte dos alunos e professores e que trabalhar o conteúdo programático de uma forma prazerosa e lúdica atrai a atenção dos alunos, demonstrando que a apresentação do jogo pode auxiliar na aprendizagem significativa das doenças parasitológicas.

O jogo foi confeccionado de forma a conter dados científicos, curiosidades, conceitos para enriquecer o conhecimento dos discentes, podendo ser utilizado por qualquer que seja o aluno ou professor que deseje informações sobre doenças parasitológicas. Foi de grande importância a coleta de informações anteriores à construção do jogo com os alunos, como também a aplicação do recurso com os mesmo, pois teve uma boa aceitação. Os educandos demonstraram entusiasmo, interesse e disposição para colaborar com a confecção desse recurso.

Grande parte das parasitoses tem características parecidas, como por exemplo, de imunização: combate ao vetor, somente utilizar água tratada, evitar contato com água parada. Sendo assim, torna-se mais interessante um jogo que amplie o número de parasitoses trabalhadas, visto que será possível utilizar características específicas de cada doença tornando mais claro e fácil a absorção do assunto por parte do aluno.

O jogo pode ser tranquilamente adaptado a qualquer disciplina tornando versátil. Pode ser utilizado como complemento de aulas anteriormente lecionadas, como também um recurso viável no auxílio do processo de ensino-aprendizagem.

\section{REFERÊNCIAS}

ALMEIDA, P. N.. Língua portuguesa e ludicidade: ensinar brincando não é brincar de ensinar. São Paulo: PUC, 2007

ALVES, E. M. S.. A ludicidade e o ensino de matemática: uma prática possível. 3 ed. Campinas: Papirus, 2006.

FIALHO, N. N.. Os jogos pedagógicos como ferramentas de ensino. In: CONGRESSO NACIONAL DE EDUCAÇÃO, 8. Anais. Curitiba: 2008.

LIMA, L. R.; GATTAMORTA, M. A.; ETEROVIC, E.; NOGUTI, R.E.. Jogo: 'Digeriu?’ - Trabalhando com a fixação e relação de conceitos de digestão. In: ENCONTRO "PERSPECTIVAS DO ENSINO DE BIOLOGIA", 8. Anais. São Paulo: Instituto de Biociências da Universidade de São Paulo, 2002. p.1-5.

LOPES, M.; G.. Jogos na educação: criar, fazer, jogar. 6 ed. São Paulo: Cortez, 2005.

MORAN, J. M.. Aprendizagem significativa. Escola de Comunicação e Artes, São Paulo, 2008. 
REY, L.. Parasitologia. 4 ed. Rio de Janeiro: Guanabara Koogan, 884pp, 2008.

TAROUCO, L. M. R.; ROLAND, L. C.; FABRE, M. C. J. M.; KONRATH, M. L. P.. Jogos educacionais: novas tecnologias na educação. In: CICLO DE PALESTRAS SOBRE NOVAS TECNOLOGIAS NA EDUCAÇÃO, 3. Anais. Porto Alegre: UFRGS, 2004.

TOSCANI, N. V.; SANTOS, A. J. D. S.; SILVA, L. L. M.; TONIAL, C. T.; CHAZAN, M.; WIEBBELLING, A. M. P.; MEZZARI, A.. Desenvolvimento e análise do jogo educativo para crianças visando à prevenção de doenças parasitológicas. Revista Interface, Botucatu, v.11, n.22, 2007. 